\title{
Desenvolvimento sustentável: o desafio da admininstração pública brasileira nas dimensões da relevância social, da prudência ecológica e da viabilidade econômica
}

Revista do

Serviço

Público

Ano 55

Número 4

Out-Dez 2004

\author{
Anderson Macedo de Jesus
}

\section{Introdução}

A humanidade e o mundo natural estão em rota de colisão. As atividades praticadas por nós, humanos, acabam por proporcionar danos irreversíveis ao ambiente, sendo necessário grande mudança na forma como nos servimos dos recursos naturais que a Terra nos proporciona.

Já sentimos a necessidade de controlar as atividades prejudiciais ao ambiente para restaurar e proteger a integridade dos sistemas terrestres dos quais dependemos. Para tanto, precisamos integrar formas alternativas de sobrevivência à nossa cultura e deixar de degradar e exaurir os recursos naturais, direta e indiretamente responsáveis pela vida saudável. A urgência de soluções para a questão ambiental transformou-a em assunto relevante nas agendas dos governos nacionais e nos fóruns de debate em âmbito internacional.

Atualmente, a gestão da questão ambiental é um grande desafio para a administração pública em todo o mundo, juntamente com as questões econômica e social. Decorrem desse desafio debates acalorados sobre as políticas e formas de gestão mais apropriadas para se garantir um modelo de desenvolvimento efetivo e não depredatório. Segundo Ignacy Sachs (2002), a solução pode estar na promoção dos três pilares básicos do desenvolvimento sustentável: a relevância social, a prudência ecológica e a viabilidade econômica.

Não obstante a reconhecida dificuldade para harmonizar esses três pilares em processo de gestão eficiente e produtivo, parece incontroversa a busca da sustentabilidade. A gravidade dos problemas gerados pela degradação ambiental exige respostas rápidas e criativas, que possam dar conta

Anderson Macedo de Jesus é Assessor Técnico da ENAP, graduado em Administração Pública pela Unesp, pósgraduando do curso de Especialização em Gestão Pública pela ENAP, professor convidado do curso de pósgraduação Lato sensu em Gestão Pública da Escola de Governo de Mato Grosso.

Contato: anderson.jesus@ enap.gov.br 
das necessidades dos cidadãos e resguardar a preservação dos recursos fundamentais para seu próprio bem-estar. Em verdade, esse é um grande desafio para os formuladores de políticas e gestores públicos, que, além de perspectiva interdisciplinar sobre a questão, não podem descuidar da complexidade que envolve a conjugação dos três pilares.

Neste ensaio, será analisada a atuação da Administração Pública Federal na gestão da questão ambiental, considerando-se a abordagem dos pilares que fundamentam o desenvolvimento sustentável. Os dados que alimentam esta análise provêm de pesquisa da jurisprudência dos tribunais. Nesta pesquisa, identificou-se e caracterizou-se a atuação de alguns órgãos do poder público que possuem grande ligação com a participação popular, a exemplo do Ministério Público e dos colegiados ambientais, e investigaram-se os parâmetros de regularidade de atuação da administração pública no uso de seu poder de polícia administrativo. O resultado mais significativo desse estudo, que será evidenciado de forma mais analítica neste ensaio, aponta para a necessidade do trabalho conjunto entre as entidades ambientalistas do setor público - sejam elas de caráter regulador ou não - como fator imprescindível para a definição, evolução e prática do desenvolvimento sustentável na sociedade brasileira.

\section{O homem e seu modelo de desenvolvimento insustentável}

O progresso científico e tecnológico que acompanhou a evolução das sociedades de mercado viabilizou a sofisticação do sistema de produção, a gênese de novas necessidades e a ampliação do consumo. Embora esse progresso tenha trazido benesses para a humanidade, também trouxe malefícios. A égide do modelo de desenvolvimento calcado no crescimento econômico a qualquer custo conduziu a maioria das sociedades ao estabelecimento de padrões insustentáveis de consumo, além de provocar, em escala mundial, distorções, tais como a concentração de renda, o aumento do nível de pobreza e o crescimento populacional desordenado. Esse modelo de desenvolvimento tornou-se insustentável graças às suas próprias contradições, que geraram os mais diversos problemas ambientais: desflorestamentos, extinção de espécies animais e vegetais, poluição, alterações climáticas, desertificação, escassez de água potável e, sobretudo, a miséria humana em diversos níveis e graus.

No Brasil, os índices de desmatamento são altos. Na Amazônia chegam a $13 \%$ da cobertura original da floresta, ocupando o segundo lugar entre os países que possuem o maior índice de desmatamento, ou seja, o país tem cerca de $16.000 \mathrm{~km}^{2}$ de área maltratada com a derrubada de árvores e incêndios provocados pela ocupação humana ${ }^{1}$. A Mata 
Atlântica cobria cerca de $15 \%$ da área nacional $\left(1.290 .692 \mathrm{~km}^{2}\right)$ por volta do século XIV, extensão que, segundo ambientalistas, foi reduzida, até 2001, para $90.438 \mathrm{~km}^{2}$.

Durante a Rio 92, foram levantados alguns dados mundiais sobre clima e efeito estufa, energia, biodiversidade, florestas, água, agricultura, pobreza, população, dívida externa e ajuda de países desenvolvidos para o desenvolvimento de países pobres. Dentre esses dados, destacam-se os seguintes: em 1990, a humanidade lançou 5,827 bilhões de toneladas de $\mathrm{CO}_{2}$ na atmosfera, acentuando o aquecimento global; em 1992, o consumo de energia no planeta foi equivalente a 8,171 trilhões de toneladas de petróleo por ano; até 1992, estimou-se que cerca de 180 espécies de animais foram extintas e outras mil estavam ameaçadas de extinção; em 1990, havia 3,960 bilhões de hectares de florestas nas diversas regiões do planeta e sua população usou cerca de $3.500 \mathrm{~km}^{3}$ de água doce por ano; em 1987, a área da terra usada na agricultura era de 14,9 milhões de km² (297 hectares para cada grupo de mil pessoas); em 1992, o planeta tinha 5,44 bilhões de habitantes; em 1990, os países subdesenvolvidos deviam US\$ 1,456 trilhões a credores externos e, em 1992, os países desenvolvidos destinavam, a título de ajuda, 0,36\% de seu PIB aos países pobres.

Os indicadores ambientais também foram negativos entre $1992 \mathrm{e}$ 2002. Dados levantados no evento sobre meio ambiente em Johannesburgo, e apresentados em 2002, na Rio +10Brasil, evidenciaram que as perspectivas e metas fixadas durante a Rio92 não evoluíram de forma positiva. Em 1999, as emissões de $\mathrm{CO}_{2}$ subiram para 6,097 bilhões de toneladas (somente 77 países ratificaram o protocolo de Kyoto até 24/8/2002); o consumo de energia subiu para o correspondente a 9,124 trilhões de toneladas de petróleo; 24 espécies (contando só os vertebrados) foram extintas desde 1992; 1.780 espécies de animais e 2.297 de plantas estão ameaçadas; em 2000, a área de floresta caiu para 3,866 bilhões, o equivalente a todo o Sudeste brasileiro (SP, MG, RJ, ES); em 2000, o consumo anual de água potável chegou a $4.000 \mathrm{~km}^{3}$ (crescimento de 12,5\%); 1,2 bilhões de pessoas vivia, em 2002, com US\$ 1 por dia (1/5 da população do planeta); a estimativa da população, em 2002, era de 6,240 bilhões (crescimento de 13\% sobre os dados de 1992); a dívida externa subiu para US\$ 2,569 trilhões em 1999 (o equivalente a cinco PIBs do Brasil); e o investimento dos países desenvolvidos caiu para $0,22 \%$, embora em 1992 o compromisso tenha sido de aumentá-lo para $0,7 \%$.

Dessa forma, as evidências parecem tornar incontestável o fato de que, pelo menos, dois dos pilares do desenvolvimento sustentável - a prudência ecológica e a relevância social -, conforme os padrões vigentes de desenvolvimento, não são muito relevantes. Considerando-se a classificação apresentada no Quadro 1, pode-se dizer que a forma de crescimento 
desordenado predomina no ambiente em que vivemos, cujos resultados são impactos ecológicos e sociais negativos e impactos econômicos somente positivos.

\section{Quadro 1: Padrões de crescimento}

\begin{tabular}{|l|c|c|c|}
\cline { 2 - 4 } \multicolumn{1}{c|}{} & \multicolumn{3}{c|}{ Impactos } \\
\hline & Econômicos & Sociais & Ecológicos \\
\hline a) Crescimento desordenado & + & - & - \\
\hline b) Crescimento social benigno & + & + & - \\
\hline $\begin{array}{l}\text { c) Crescimento ambientalmente } \\
\text { sustentável }\end{array}$ & + & - & + \\
\hline d) Desenvolvimento & + & + & + \\
\hline
\end{tabular}

(SACHS, 2002)

\section{O papel da administração pública na gestão ambiental}

O enfrentamento das contradições do "modelo de desenvolvimento insustentável" envolve diversas dimensões ou esferas de ação. Parece haver consenso de que a educação das novas gerações, a conscientização dos setores produtivos e a condução do tema para os debates no âmbito internacional constituem ações fundamentais a médio e longo prazo. Não obstante, há também o reconhecimento de que uma ação imediata do poder público é essencial para regular os procedimentos e evitar abusos no uso dos recursos naturais.

É pelo poder de polícia administrativo que a administração pública protege o meio ambiente. O uso da força do Estado, por meio da coercibilidade, permite a materialização das sanções administrativas dos agentes competentes (MuKaI, 1998). Esse poder de polícia é parte integrante da administração pública, que tem como objetivo limitar e disciplinar direito, interesse e liberdade, regulando condutas para evitar abusos (Freund, Ernest apud Franco Sobrinho, 1951. Sirvinskas, 2002. Machado, 2002. Lopes, 1998. B ARBosA, 1958. TÁcITo, 1952).

No Brasil, o poder de polícia ambiental administrativo é exercido pelos órgãos do Sistema Nacional do Meio Ambiente (Sisnama), previsto no art. 6º da Lei no 6.938/81. Esses órgãos são compostos pelos Conselhos Ambientais ligados ao Ministério do Meio Ambiente, a saber:

- Conselho Nacional do Meio Ambiente (Conama);

- Conselho Nacional da Amazônia Legal;

- Conselho Nacional dos Recursos Hídricos e o Comitê do Fundo Nacional do Meio Ambiente, que formam os órgãos consultivos e deliberativos; 
- Conselho de Governo, órgão superior presidido pelo presidente da República;

- Instituto Brasileiro do Meio Ambiente e dos Recursos Naturais Renováveis (Ibama), órgão executor;

- Órgãos seccionais, que são entidades colegiadas instituídas por alguns estados, como o Conselho Estadual de Proteção Ambiental (Cepram), a Comissão de Política Ambiental (Copam) e a Comissão Estadual de Controle Ambiental (Ceca);

- Órgãos setoriais, que reúnem as entidades federais da administração direta ou indireta, encarregados de proteger o meio ambiente;

- Órgãos locais que se referem às entidades municipais de meio ambiente.

Existem também órgãos ambientalistas distribuídos pelas regiões do país, a saber:

- Região Sul - Instituto Ambiental do Paraná (IAP), Fundação do Meio Ambiente (Fatma) e Fundação Estadual de Proteção Ambiental (Fepam);

- Região Sudeste - Companhia de Tecnologia de Saneamento Ambiental (Cetesb), Fundação Estadual do Meio Ambiente (Feam) e Fundação Estadual de Engenharia do Meio Ambiente (Feema);

- Região Norte - Secretaria Executiva de Ciência, Tecnologia e Meio Ambiente (Sectam);

- Região Nordeste - Centro de Recursos Ambientais (CRA), Superintendência Estadual de Meio Ambiente (Semace), Instituto de Desenvolvimento Econômico e Meio Ambiente (Idema) e Administração Estadual do Meio Ambiente (Adema);

- Região Centro-Oeste - Fundação Estadual do Meio Ambiente (Femago) e Secretaria de Meio Ambiente (Sema).

Esses órgãos ou entidades colegiadas, que fazem parte do Sisnama, abrem a todo cidadão a condição de fazer valer seus direitos e propostas por meio deles. É importante salientar o poder de polícia que têm alguns desses órgãos, que dão legitimidade de coerção às infrações locais. Ainda destaque-se que a maior parte dos atos de polícia, embora discricionários em certos casos, é vinculada e auto-executória, tratando-se sempre de aplicação de sanções. Todavia, existe o oferecimento da ampla defesa, uma vez que as sanções envolvem medidas como multa, interdição de atividade e de estabelecimento, demolições, embargos de obras, proibição de fabricação e comércio de produtos.

\section{A participação dos cidadãos e o Ministério Público}

Além das entidades que exercem o poder de polícia, o Estado dispõe de instâncias em que o próprio cidadão pode-se fazer presente nas ações 
de proteção do meio ambiente. Destaca-se, nesse caso, o Ministério Público $^{2}$. Pode-se afirmar que essa entidade resulta do próprio processo de aperfeiçoamento da legislação brasileira, que a viabilizou como ente responsável pela iniciação e interação ${ }^{3}$ entre os cidadãos, o meio ambiente e toda administração pública.

Com o advento da Constituição Federativa do Brasil de 1988, a administração pública e os cidadãos tornaram-se co-responsáveis pelo zelo ao meio ambiente e, conseqüentemente, por sua qualidade. Ou seja, à população coube a responsabilidade de denunciar tudo aquilo que prejudique o meio ambiente e seu bem-estar, e à administração pública restou a responsabilidade de cumprir, mediante coação, toda e qualquer prática que venha prejudicar tanto o meio ambiente quanto a boa qualidade de vida dos cidadãos. $\mathrm{O}$ art. 225 da mesma Constituição deixa evidente essa situação, mas a pesquisa realizada para diagnosticar a atuação da administração pública na gestão da questão ambientalista permitiu identificar que a conscientização desse dever ainda está longe de acontecer, em parte devido ao próprio insucesso das entidades responsáveis pela gestão da questão ambiental e da preservação dos recursos naturais.

De qualquer forma, há ocorrências positivas na administração pública, o que pode ser verificado com a implantação da ação civil pública, que tem como objetivo, além de assegurar o controle social, garantir a proteção do patrimônio público e social e do meio ambiente. Para tanto, o Ministério Público desempenha papel muito importante. Na condição de proponente das ações judiciais de natureza civil, que visam recuperar ou evitar danos ao meio ambiente e, conseqüentemente, à população (MILARÉ, 2001), essa entidade abre um canal na administração pública para a representação dos interesses sociais.

Podemos identificar, em parte das atribuições do Ministério Público, o "princípio da precaução", que está presente também na Constituição Federativa do Brasil ${ }^{5}$, como principio garantidor de vida sadia e qualitativa para as gerações presentes e futuras (MACHADO, 2002). Esse princípio é tão significativo que o não-cumprimento das medidas de precaução contraria não só a moralidade, mas a própria legalidade administrativa, porque se estende ao poder de polícia, ou seja, entra no domínio do direito público, que tem como função garantir o bem-estar social, devendo tomar medidas que limitem ou suspendam as liberdades dos cidadãos, caso a situação o exija.

O Ministério Público é uma das instituições que mais receberam a atenção dos constituintes em 1988. Entre as grandes inovações devido à sua criação, encontra-se a Lei n⿳0 ${ }^{6} .938 / 81$, regulamentada pelo Decreto Federal $\mathrm{n}^{\circ} \mathrm{88.351}$, de $1^{\circ}$ 6.1983, que instituiu a responsabilidade do poluidor, independente da culpa (responsabilidade objetiva) ${ }^{3}$, e a faculdade de o 
Ministério Público propor ações de natureza civil. De acordo com Milaré (2001, p. 270), o Brasil foi "um dos pioneiros no mundo de uma nova função do Ministério Público, fazendo com que este se firmasse como a instituição mais bem credenciada para tutela dos interesses sociais, difusos e coletivos, na ordem civil. Isso sem prejuízo de sua tradicional atuação dos crimes ecológicos".

Cabe ao Ministério Público, como canal de representação da sociedade, interagir com o Judiciário, por meio do procurador-geral da República, para julgar os casos inseridos em sua competência. Ou seja, somente por meio dessa interação e do poder de polícia da administração pública é que os direitos da cidadania poderão ser exercidos e as ameaças, resolvidas. Tal fato realça o importante papel reservado ao Ministério Público e ao restante da administração pública, na apreciação das necessidades da sociedade e manutenção do bem-estar social.

A interação entre os cidadãos e o Ministério Público e entre essa entidade e o Poder Judiciário constitui importante possibilidade de ação consciente da sociedade, fazendo que apareçam grandes controvérsias na promoção de meio ambiente sadio e sustentável, ao qual homens e mulheres têm direito. É fato que estamos muito longe da conscientização plena em torno da questão ambiental, porém abre-se caminho a ser seguido, sobretudo quando se sabe que, por tantas vezes, os cidadãos ignoram seus legítimos direitos e se fazem alijados das políticas públicas e dos direitos, por desconhecimento e falta de vivência política e social, calandose atônitos diante de abusos ambientais e sociais.

É necessário, então, salientar que todo cidadão tem o direito de requerer do poder público e dos órgãos ambientais as informações necessárias de seu interesse particular ou coletivo, principalmente quando o assunto se relaciona com a preservação e manutenção do meio ambiente, que deve ser assegurado e protegido como patrimônio público ${ }^{7}$ (art. 2º ${ }^{-}$inciso I, da Lei no 6.938/81). Nesse sentido, o Ministério Público surge como coadjuvante e pode estar a serviço do cidadão que, por muitas vezes, sente-se desamparado ou incapacitado de arcar com o ônus de lutas judiciais onerosas contra interesses de grandes empresas ou mesmo contra o próprio Estado, que, no papel de empreendedor, pode agir de forma irregular no trato com o meio ambiente ou ser omisso, como gestor da política pública ou agente regulador no exercício de seu dever constitucional.

\section{Diagnóstico da atuação da administração pública na gestão da questão ambiental}

Não obstante a evidência dos progressos obtidos na gestão da política ambiental com a atuação do Ministério Público, é importante 
considerar a atuação da administração pública em seu conjunto, para avaliação adequada dessa gestão, particularmente no que diz respeito ao poder de regulação e fiscalização do Estado. Para tanto, o levantamento e a análise da jurisprudência dos tribunais brasileiros podem ser elucidativos. Com esse intuito, foram pesquisados os acórdãos (jurisprudência) ${ }^{8}$ dos últimos 50 anos (1950-2001), referentes ao combate da degradação dos recursos naturais (florestas brasileiras). A análise dos dados permitiu verificar alguns aspectos importantes sobre essa questão.

Em primeiro lugar, foi possível verificar que o maior número de acórdãos, cerca de 79\%, concentrou-se na década de 1990 (veja Gráfico 1).

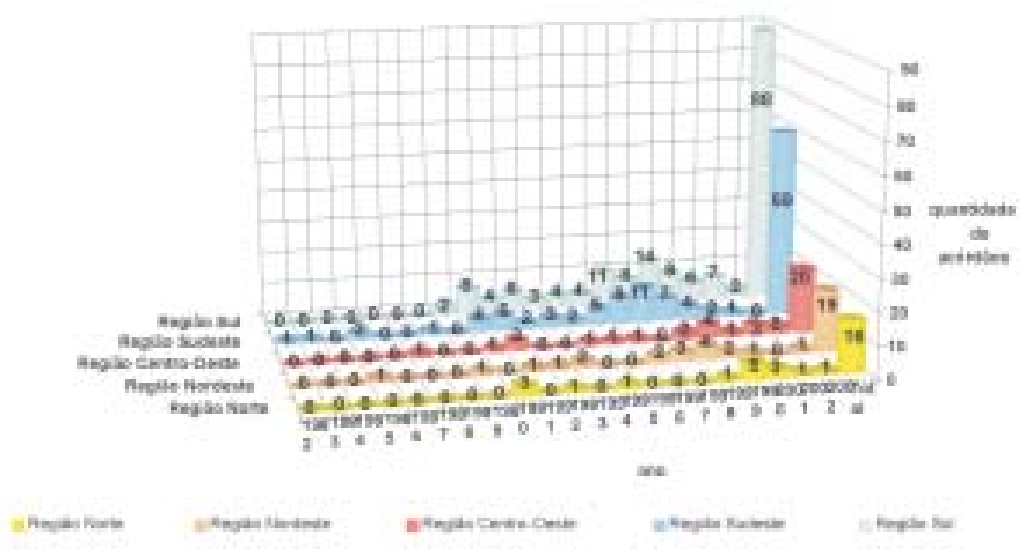

\section{Gráfico 1: Ritmo da incidência de acórdãos registrados após a Constituição Federal de 1988}

Tal ocorrência parece apontar para as alterações promovidas pela Constituição de 1988, já mencionadas neste ensaio, que responsabilizaram pela tutela do meio ambiente tanto a administração pública quanto o cidadão. Com elas também houve a ampliação das atribuições do Ministério Público e do Judiciário, inclusive do Supremo Tribunal Federal (STF), além da criação do Superior Tribunal de Justiça (STJ). Somam-se a esses fatos de natureza constitucional a difusão da educação ambiental e o crescimento dos movimentos ambientalistas mediante a ação de ONGs. Essas ocorrências auxiliaram na formação de ambiente mais crítico, viabilizando o encaminhamento de denúncias e ações judiciais outrora não observadas com a mesma freqüência. Em segundo lugar, os números levantados permitem observar em que regiões e em quais períodos cresceram as incidências dos casos de acionamento do poder de polícia administrativo, ou seja, os casos de atuação da administração pública contra a degradação do meio ambiente, e, conseqüentemente, da intervenção 
judiciária. Como tendência mais geral, há maior incidência de acórdãos nas regiões Sul e Sudeste do que nas regiões Centro-Oeste, Norte e Nordeste, em que se nota uma significativa diminuição no número de acórdãos.

As regiões mais ricas do país (Regiões Sul e Sudeste) acumularam um total de $73 \%$ dos acórdãos coletados, enquanto as regiões mais pobres (Norte, Centro-Oeste e Nordeste), os 27\% restantes (veja Gráfico 2).

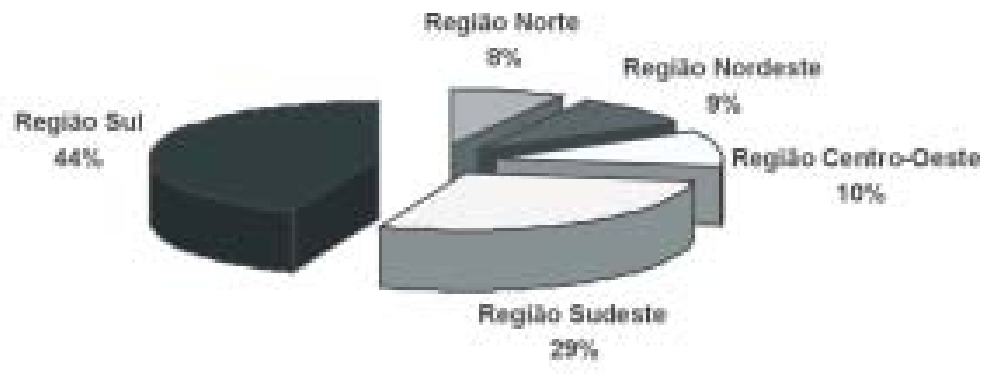

Gráfico 2: Distribuição dos acórdãos encontrados e analisados

O Estado de Santa Catarina foi o que mais obteve crescimento da incidência do acionamento das polícias administrativa e judiciária nos anos de 1990, seguido por São Paulo, também com grande crescimento de casos durante a mesma década.

Essa concentração também é notada nos casos do Rio Grande do Sul e de Minas Gerais. Paraná e Rio de Janeiro vêm em seguida (veja Gráfico 3), enquanto no Distrito Federal, em Goiás, em Pernambuco, na Bahia, no Pará, no Acre, no Amazonas e nos demais estados periféricos, como Amapá, Roraima, Rondônia e Tocantins, onde a pobreza e a desinformação são maiores, ocorrem números inexpressivos de incidência da polícia judiciária e administrativa contra a degradação dos recursos naturais (veja Gráfico 4). 


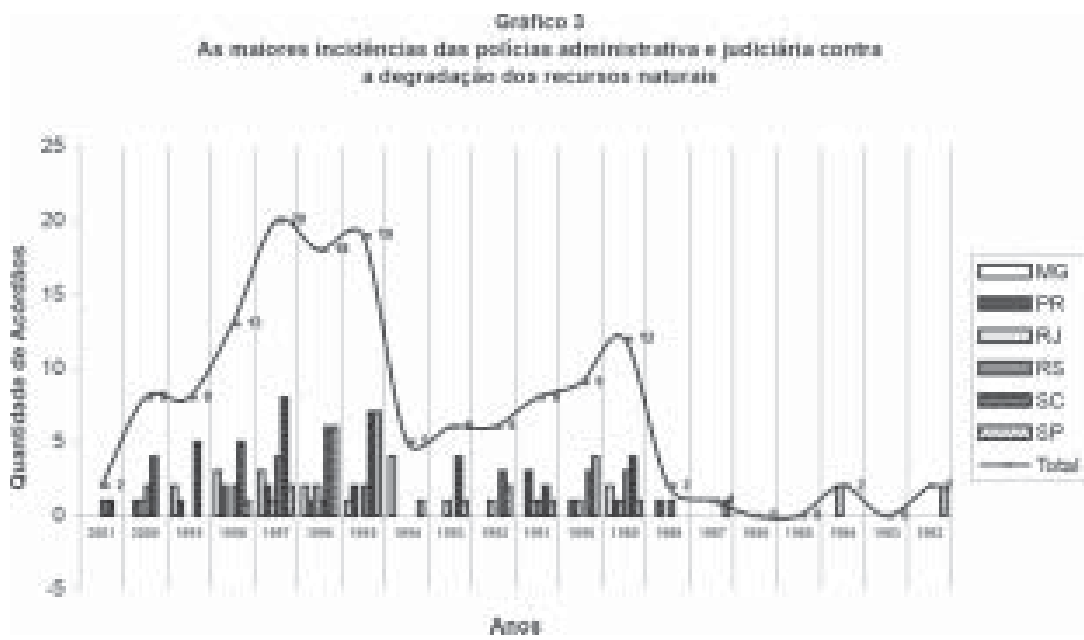

Gráfico 3: As maiores incidências das polícias administrativa e judiciária contra a degradação dos recursos naturais

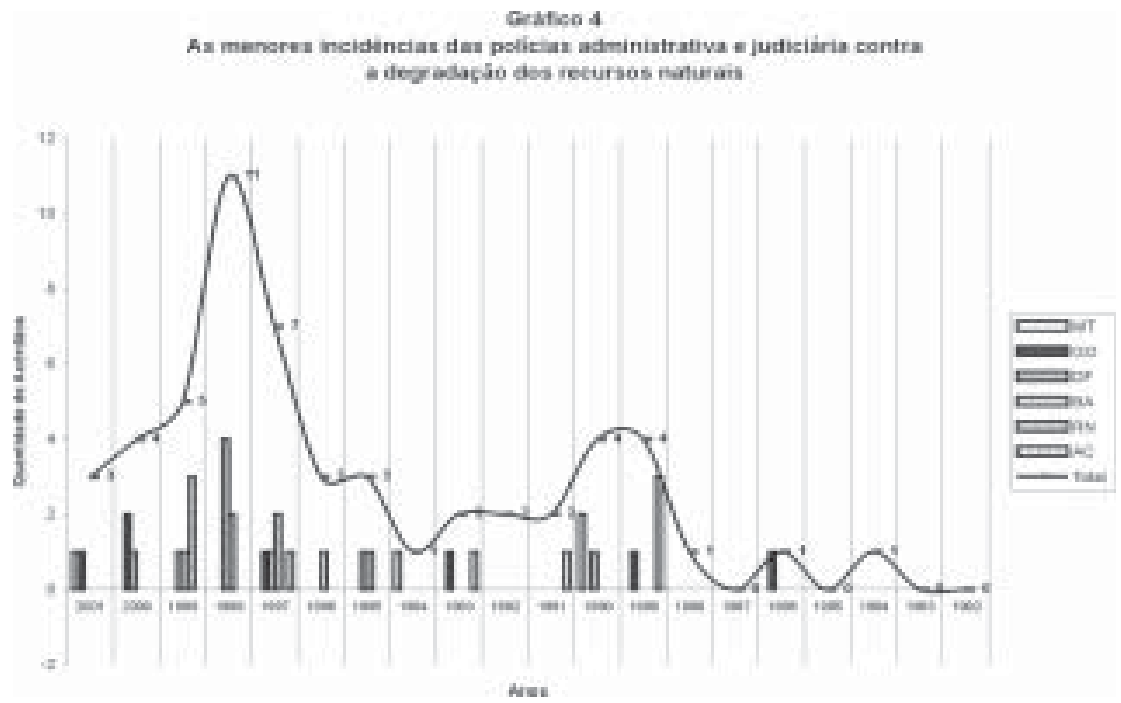

Gráfico 4: As menores incidências das polícias administrativa e judiciária contra a degradação dos recursos naturais

A análise da jurisprudência permitiu o registro de três situações distintas, segundo as quais os acórdãos foram agrupados.

A primeira situação ${ }^{9}$ deixa evidente a grande importância do Ministério Público para a boa atuação da administração pública, o qual ora aciona a si próprio, ora é acionado pela coletividade e também por 
meio de litisconsórcio ${ }^{10}$ com outros órgãos, movendo ações civis públicas

contra empresas particulares (madeireiras, usinas, fazendas, etc.) e, até mesmo, contra a própria administração pública (governos de estado e município). Exemplo deste último caso são as ações contra o Instituto Brasileiro do Meio Ambiente e Recursos Naturais Renováveis (Ibama) e o ex-Instituto Brasileiro de Desenvolvimento Florestal (IBDF), antecessor do Ibama.

Assim, os acórdãos permitiram observar que o Ministério Público tem exercido papel de destaque na defesa da preservação ambiental. Nota-se que essa entidade tem agido para que os interesses públicos sejam legalmente respeitados, coibindo as práticas deletérias que, por vezes, passam despercebidas pelos órgãos colegiados que exercem o poder de polícia administrativo, e tem cumprido com o princípio da precaução, agindo de forma antecipada aos perigos iminentes.

O Ministério Público, por diversas vezes, tem-se deparado com o problema da derrubada de milhares de hectares de florestas virgens por grandes fazendeiros para a formação de pastagens com vista à criação de gado ou por madeireiras para a comercialização de madeira, os quais, sem a devida licença, são, muitas vezes, autuados e punidos por desmatar e/ou estocar madeira. De acordo com estimativas do Ibama $^{11}$, as madeireiras foram responsáveis pela abertura de mais de 3 mil quilômetros de estradas ilegais nos últimos anos só no sul do Pará. Muitas dessas madeireiras, segundo o Ibama, são multinacionais de origem asiática, sem contar com a ação das mais de 7 mil empresas registradas na Amazônia.

Também tem agido o Ministério Público contra alguns planos de assentamentos que geram desflorestamento. Houve autuação do Instituto Nacional de Colonização e Reforma Agrária (Incra) pela derrubada de florestas com a intenção de implantar assentamentos. O Ministério de Política Fundiária, para não prejudicar o meio ambiente sadio, proibiu, em outubro de 1999, a desapropriação de terras para fins de reforma agrária em locais de mata ciliar.

A crescimento da cultura da soja na região amazônica, por meio da aquisição de áreas desmatadas para o plantio, tornou-se problema preocupante para a sociedade e para o poder público e fez que o Ministério do Meio Ambiente, em ação desesperada, limitasse o corte das florestas para o cultivo em 3 hectares ao ano. Embora essa medida amenize o problema, parece não ser a mais adequada para resolvê-lo definitivamente.

Em 2001, o Ministério do Meio Ambiente instituiu o licenciamento ambiental em propriedade rural, especificamente em municípios de Rondônia e do Pará, que, de acordo com o Instituto de Pesquisas Espaciais (Inpe), foram os estados responsáveis por cerca de $80 \%$ do desmatamento na Amazônia, entre 1997 e 1999. 
A segunda situação ${ }^{12}$ envolve a atuação do órgão executor, o Ibama, ora por sua própria atuação, ora por sua atuação com órgãos colegiados ambientais, como a Fundação do Meio Ambiente (Fatma), que atua na Região Sul, e a Companhia de Tecnologia de Saneamento Ambiental (Cetesb), da Região Sudeste. Os acórdãos analisados evidenciam a ação incisiva do Ibama na autuação de empresas diversas, inclusive rurais e agroindustriais e da própria administração pública por atuação de governos estaduais e municipais. Observa-se ainda, entre suas atividades, a cassação de licenças e de cotas para a exploração de matas, o indeferimento de autorização para desmatamento e a negação de renovação de prazos, evidenciando postura de intolerância com relação aos abusos cometidos contra o meio ambiente.

A terceira e última situação ${ }^{13}$ reúne os acórdãos referentes à ação da administração pública estadual e municipal. Nesse caso, o que salta aos olhos é a ocorrência pouco significativa de atos propostos e a inexpressiva participação dos governos estaduais e municipais na promoção de ações contra crime ambiental. Ao contrário, os governos locais estão sendo mais coagidos que coativos.

Os governos locais não têm exercido adequadamente seu dever de zelar pelo meio ambiente sadio e equilibrado e, por vezes, são os autores da própria contravenção, restando aos órgãos da Administração Pública Federal (Ministério Público, órgão executor e órgãos colegiados) a ação contra atos irregulares de entidades públicas estaduais ou municipais.

Diante da análise dos acórdãos, os governos locais encontram-se muito mais comprometidos com o empenho fiscal (interesses econômicos), e, dessa forma, tornam-se coniventes na implementação de projetos econômicos questionáveis do ponto de vista ambiental, a exemplo dos empreendimentos de grandes latifundiários, que derrubam milhares de hectares de florestas para o plantio da soja. Nesse caso, o poder público reforça a expansão agropecuária, porque o Brasil é um dos países com maior potencialidade de expansão dessa natureza. Segundo a Organização das Nações Unidas para Agricultura e Alimentação (FAO), a área cultivada do país cresceu de 187 milhões para 250 milhões de hectares, o que representa crescimento de 34\%, entre 1969 e 1999, e passou a ter o segundo maior rebanho bovino do mundo, ficando atrás apenas da Índia, além do terceiro maior rebanho de suínos e frangos, posicionando-se apenas depois da China e dos EUA.

Os grandes fazendeiros devastam quantidades imensas de florestas de preservação permanente contidas em suas propriedades para fins agropecuários. Assim, pode-se perceber a expansão nas chamadas novas fronteiras agrícolas, em regiões de menor densidade populacional, especialmente o Centro-Oeste e Norte. 
De acordo com o IBGE, em 1999 a produtividade de Mato Grosso (MT) na cultura de soja (2.836 quilos por hectare) superou a do líder Paraná (PR) (2.781 quilos por hectare). Essas estatísticas evidenciam a importância econômica da agropecuária na geração de recursos para obtenção de balança comercial favorável ao setor, ou seja, a diferença entre o valor das exportações e o valor das importações de produtos agropecuários.

A safra brasileira de grãos estimada para 2001 foi de 98,298 milhões de toneladas, segundo o IBGE, sendo o volume $18,08 \%$ superior ao de 2000. A Região Sul, a mais devastada, é responsável por metade dessa produção: 49,349 milhões de toneladas. Destaca-se também a Região Centro-Oeste.

A análise dos acórdãos incluídos na terceira situação permite verificar, portanto, a excessiva preocupação dos governos estaduais e municipais com o aquecimento da economia local e com a arrecadação, fundamental para o equilíbrio das contas públicas, em detrimento de ação mais racional e menos destrutiva dos recursos naturais e do bem-estar coletivo.

\section{Equívocos da administração pública na gestão da questão ambiental}

A pesquisa dos acórdãos foi um exercício importante para evidenciar aspectos positivos e negativos na ação do poder público na gestão da questão ambiental. Embora entidades da Administração Pública Federal estejam realizando trabalhos significativos na regulamentação e fiscalização dos abusos e crimes contra o meio ambiente, os governos locais ausentam-se na provocação do Poder Judiciário com o propósito de cuidar ativamente do meio ambiente. Esses mesmos governos são algumas vezes ${ }^{14}$ autuados, ao autorizarem o desmatamento de certas áreas de preservação permanente. Nem sempre os projetos que dão origem às autuações, por ocupação irregular de áreas, são de natureza meramente econômica, como os destinados a assentamentos de famílias, à criação de depósitos de detritos ou ao lazer (construção de estádios e anfiteatros). Entretanto, a maioria dos projetos prioriza questões de caráter estritamente econômico. A pesquisa permitiu verificar, na análise de 78 acórdãos, por exemplo, a cessão de autorização indevida para o desmatamento de áreas extensas. Entre esses processos, 52 referem-se à Região Centro-Oeste, onde a monocultura da soja mais cresce no país. Há, portanto, necessidade de redefinição dos parâmetros do desenvolvimento regional e participação mais significativa dos governos locais na busca de alternativas sustentáveis.

Não é suficiente a atuação exemplar dos governos na manutenção do equilíbrio fiscal ou na busca de meios para a geração de empregos. Tais 
medidas não devem ser divorciadas do esforço da conquista de crescimento sustentável. É urgente, por exemplo, o planejamento adequado para barrar a ocupação desordenada em certas regiões do país, em vista do crescimento populacional, que vem causando sérios impactos no meio ambiente, como a ocupação de áreas de mananciais, o desflorestamento e a poluição do ambiente. Torna-se necessária, portanto, a execução de programas organizados e competentes planos de trabalho (planos diretores) com ações de curto, médio e longo prazo, com vistas à ocupação mais ordenada principalmente dos espaços próximos dos grandes centros urbanos.

Além das medidas oficiais que às entidades públicas cabem como obrigação, é importante considerar o trabalho colaborativo das entidades não governamentais e dos próprios cidadãos. Nota-se, cada vez mais, que cidadãos acionam o Ministério Público e os órgãos colegiados para a defesa dos seus direitos e do meio ambiente ${ }^{15}$. Esse potencial de participação política e social é fundamental para o fortalecimento das instituições em uma democracia e, se as entidades ambientalistas oficiais souberem somar esforços, poderão encontrar os meios necessários para a definição de desenvolvimento que contemple a viabilidade econômica, sem abandonar a relevância social e a prudência ecológica.

\section{Conclusão}

Há necessidade de que a sociedade seja mais equânime e informada sobre seus direitos e deveres relativos ao meio ambiente. Ao lado da reivindicação de maior participação social - inclusão social - na vida política e decisória do país, que tem marcado as últimas décadas, o debate sobre o uso dos recursos naturais tem-se avolumado no Brasil. Além das entidades públicas, o tema ocupa espaço na agenda dos partidos políticos, nas discussões dos movimentos sociais e nos currículos escolares. Esse fato é a evidência de que a sociedade começa a perceber a ênfase dada à questão econômica pela corrida do desenvolvimento e as suas limitações para a conquista de crescimento real e promissor para todos. Além disso, a marginalização da questão social nas agendas de governo tem gerado reação da população, que revela nas urnas a necessidade de representantes públicos mais identificados com essa questão. Junto com a reivindicação de melhor nível de vida, tem sido adicionada a preocupação com o meio ambiente. Essa questão adquire, atualmente, a relevância de problema público que transcende os limites nacionais. A exigência de modelo de desenvolvimento equilibrado vem surgindo no cenário mundial como forma alternativa do aproveitamento racional e sustentável da natureza em benefício das populações (prudência ecológica), no sentido 
de que elas próprias possam incorporar a importância da preservação como componente estratégico de desenvolvimento (SACHS, 2002).

O estudo da jurisprudência e dos acórdãos evidenciou, justamente, a situação de indiferença de parte da administração pública ao gerir a questão ambiental. Essa indiferença é revelada no descaso com a questão do meio ambiente e com a falta de sensibilidade para garantir a qualidade de vida dos cidadãos. Por diversas vezes, entidades públicas estaduais e municipais foram autuadas pelo Ministério Público por omissão de seu dever ou até mesmo pela concessão do ato lesivo a terceiros, que passaram a prejudicar o meio ambiente e, conseqüentemente, a sociedade ${ }^{16}$. Nesses atos, os interesses econômicos foram postos em evidência na escala de prioridades, acima da garantia do bem-estar social da atual e das futuras gerações.

O desenvolvimento sustentável só poderá acontecer mediante a gestão das três bases que o sustenta: viabilidade econômica, relevância social e prudência ecológica. Sem elas poderá haver alguma forma de desenvolvimento, mas certamente será desequilibrado. Esse modelo de desenvolvimento sem equilíbrio não parece ser nem o sentimento nem o ideal dos brasileiros, o que a Constituinte de 1988 consegui captar, pois o art. 225, caput, da Constituição Federativa do Brasil reza: "Todos têm direito ao meio ambiente ecologicamente equilibrado, bem de uso comum do povo e essencial à sadia qualidade de vida, impondo-se ao poder público e à coletividade o dever de defendê-lo e preservá-lo para as presentes e futuras gerações". Assim, a Constituição coloca o poder público e a coletividade como co-responsáveis pela defesa do meio ambiente, tendo o dever de preservá-lo para as presentes e futuras gerações, ou seja, prevê o desenvolvimento sustentável baseado na perpetuação do meio, todavia, calcado no aperfeiçoamento da participação, educação e interação do povo com o poder público e centrado na consciência de um ente coletivo.

Esse é um desafio para o poder público e para a sociedade no Brasil. O seu sucesso depende do aperfeiçoamento das entidades públicas na gestão das políticas, mas também do potencial colaborativo da sociedade e de seu crescente processo de conscientização e participação. A pesquisa apresentada neste ensaio foi reveladora do importante papel que têm desempenhado os órgãos colegiados, os órgãos executores e o Ministério Público na gestão da questão ambiental, mas também de vários problemas que demandam soluções urgentes.

Identificou-se, no decorrer do trabalho, a grande dificuldade que os órgãos colegiados ${ }^{17}$ e o órgão executor têm de fiscalizar todo o território nacional devido aos seus escassos recursos humanos e materiais. As ações do Instituto Brasileiro do Meio Ambiente e Recursos Naturais Renováveis (Ibama) são extremamente tímidas quando confrontadas com a dimensão e exigências do país. O instituto contava, em 2002, ano em que se realizou 
a pesquisa, com apenas 275 fiscais para cuidar de toda região da Amazônia Legal $^{18}$, que tem cerca de 5,1 milhões de quilômetros quadrados, o que equivale a um funcionário para cada 18,5 mil quilômetros quadrados. Essa deficiência poderia ser suprida com recursos humanos devidamente qualificados e recursos materiais suficientes para aparelhar de forma satisfatória esses agentes, proporcionando melhoria no rendimento da atuação dos órgãos colegiados e executores, no combate ao notório crescimento da demanda das práticas deletérias explicitadas neste ensaio.

Foi possível verificar, ainda, que os governos estaduais e municipais atuam de forma insatisfatória no que diz respeito ao uso do poder de polícia administrativo (ato administrativo) para solucionar as práticas destrutivas ao meio ambiente. O uso desse recurso constitui ação poderosa no combate aos abusos e crimes contra o ambiente, porque ele concede à administração pública o poder para "adquirir, resguardar, transferir, extinguir e declarar direitos, ou impor obrigações aos administrados ou a si própria" (MeIRELES, 1987). Entretanto, o fortalecimento do poder de polícia das entidades públicas não é suficiente. A análise dos dados levantados na pesquisa permite perceber quanto é importante a participação da sociedade na gestão das políticas de meio ambiente, até mesmo porque os órgãos públicos responsáveis pela questão ambiental contam com as denúncias da população. É fundamental, portanto, que se ampliem ações informativas e educativas para tornar mais elevados os níveis de conscientização. A interação da sociedade consciente com os órgãos do poder público cria ambiente propício à luta pela preservação dos recursos naturais, estimulando o cidadão às denúncias, ao acionamento do Ministério Público e à conseqüente provocação do Poder Judiciário.

Tais ações, complementadas pelo suprimento de recursos materiais e humanos, atualmente precários e escassos, provavelmente conduzirão à melhoria da atuação da administração pública e do uso de poder de polícia ambiental administrativo contra as práticas deletérias ao meio ambiente. Nesse contexto, desde que se garantam, nos projetos governamentais, a relevância social, levando-se em conta a participação da sociedade, suas necessidades, seus direitos e deveres; a prudência ecológica, que se materializa no uso sustentado dos recursos naturais; e a viabilidade econômica, que se traduz no uso racional dos recursos, certamente será possível a construção de novo modelo de desenvolvimento capaz de gerar o bem-estar humano sem a paradoxal destruição do ambiente. 
* Este artigo foi baseado em dois trabalhos apresentados, respectivamente, no II Congresso Nacional de Administração Pública do Instituto Nacional de Administração de Portugal (INA), em Lisboa, e no IX Congreso Internacional del CLAD sobre la Reforma del Estado y de la Administración Pública, em Madri, ambos em 2004.

1 Todos os dados apresentados nesse item foram extraídos do Caderno Especial 1 Rio +10 , Folha de S. Paulo, 24 de agosto de 2002, que se embasou em documentos oficiais da Rio +5 e Rio +10 .

2 O Ministério Público, instituição pertinente ao Poder Executivo, portanto parte da administração pública, mantém independência que suscita a idéia de que não faz parte do Executivo, constituindo um quarto poder independente, representante dos cidadãos nas ações civis públicas e coletivas, já que possui atribuições e orçamento próprio (art. 127, $\S 3^{\circ}$, da CF)

3 Diz-se que há essa interação porque o cidadão, ao sentir seu bem-estar social prejudicado devido a abusos contra o meio ambiente, que afetam a vida sadia, pode, por meio do Ministério Público, acionar o Poder Judiciário, que tomará as medidas necessárias. Cabe também à administração pública em geral fazer melhor uso do seu poder coativo e preventivo em benefício do cidadão mediante o uso de atos administrativos, o que daria mais suporte à existência dessa interação.

4 Carta da Conferência das Nações Unidas sobre o Meio Ambiente e Desenvolvimento, realizada no Rio de Janeiro, de 3 a 14 de junho de 1992, em que o princípio no 15 explicita: "In order to protect the environment, the precautionary approach shall be widely applied by states according of their capabilities. Where there are threats of serious or irreversible, lack of full scientifically certainty shall not be used as a reason for postponing cost-effective measures to prevent environmental degradation." (MACHADO, 2002. DiAs, 2001).

5 O art. 225, caput, da Constituição Federal reza: "Todos têm direito ao meio ambiente ecologicamente equilibrado, bem de uso comum do povo e essencial à sadia qualidade de vida, impondo-se ao poder público e à coletividade o dever de defendê-lo e preservá-lo para as presentes e futuras gerações".

6 "A teoria objetiva não exige a demonstração da culpa, ou seja, o agente responderá pelos danos causados independentemente da culpa. Basta a demonstração da existência do fato ou do ato - o dano e o nexo causal" (SIRVINSKAS, 2002).

7 Esse direito está previsto na Constituição Federativa do Brasil, no seu art. 5o, inciso XXXIII, que reza: "Todos têm o direito a receber dos órgãos públicos informações de seu interesse particular, ou de interesse coletivo ou geral, que serão prestadas no prazo da lei, sob pena de responsabilidade, ressalvadas aquelas cujo sigilo seja regulamentado pela Lei no 9.051, de 18 de maio de 1995" (SIRVINSKAS, 2002).

$8 \mathrm{O}$ acesso à jurisprudência, depois de pesquisas em vários sites, foi feito no do Conselho de Justiça Federal (CJF), detentor de um sistema que efetua pesquisa de jurisprudência nos seguintes tribunais: Supremo Tribunal Federal (STF), Superior Tribunal de Justiça (STJ), Tribunal Regional Federal 1 1 ${ }^{\mathrm{a}}$ região (TRF 1), Tribunal Regional Federal $2^{\mathrm{a}}$ região

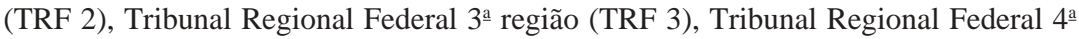
região (TRF 4) e Tribunal Regional Federal 5 a região (TRF 5), desta maneira, obtivemos a somatória de 154 acórdãos de diferentes regiões do país. Foi pesquisada também a jurisprudência do Supremo Tribunal Federal (STF), do Superior Tribunal de Justiça (STJ) e dos Tribunais de Justiça de todos os estados, totalizando 202 acórdãos. A pesquisa da jurisprudência específica ocorreu durante o mês de julho de 2002. Nenhum 
acórdão de Sergipe, Paraíba, Alagoas, Piauí, Tocantins e Amapá foi incluído nesta pesquisa. Alguns desses estados não dispunham de jurisprudência disponível em seus sites, o que gerou visitas locais, mas sem que houvesse sucesso na obtenção das informações. Outros estados nem sequer dispunham de jurisprudência disponível sobre o assunto.

9 Esta primeira situação foi caracterizada com a identificação de 132 acórdãos em que o Ministério Público aciona o Poder Judiciário contra as práticas deletérias ao meio ambiente.

${ }^{10}$ Litisconsórcio, de acordo com o Dicionário Houaiss da língua portuguesa, é uma pluralidade de partes com a mesma posição (co-autores ou co-réus) numa disputa judicial.

${ }^{11}$ Acesso ao site do Ibama em 26 de outubro de 2002, às 10h20: <www.ibama.gov.br〉.

${ }^{12}$ A segunda situação foi caracterizada com a identificação de 62 acórdãos, em que os órgãos colegiados ambientais estaduais e o órgão executor atuaram contra as práticas deletérias ao meio ambiente.

${ }^{13}$ A terceira e última situação identificada na análise dos últimos oito acórdãos foi a ínfima atuação da administração pública (governos estaduais e municipais) contra as práticas deletérias ao meio ambiente. Ou seja, os governos estaduais e municipais não fazem uso do ato administrativo inerente à administração pública. Como se não bastasse a falta do uso das sanções administrativas, os governos são autuados pelos próprios componentes da administração pública (Ministério Público e Ibama), causando grande desconforto a ela e péssima imagem dela.

${ }^{14}$ A administração pública foi autuada pelo Poder Judiciário por conta da autorização indevida de desmatamento, em 78 acórdãos dos 202 analisados.

${ }^{15}$ A atuação da população, ainda muito ausente na defesa de seus direitos e do meio ambiente, foi identificada em 16 acórdãos. Em 12 destes, a população acionou o Ministério Público e, nos outros quatro, acionou alguns órgãos colegiados ambientais de seus estados de origem.

${ }^{16}$ Dos 202 acórdãos analisados, 158 continham a administração pública como ente coagido pelo Ministério Público e/ou Ibama, ao viabilizar, de alguma forma, a degradação do meio ambiente e, conseqüentemente, da qualidade de vida dos cidadãos.

${ }^{17}$ Importante salientar o poder de polícia que alguns desses órgãos possuem, dando legitimidade de coerção às infrações locais.

${ }^{18}$ Dados do Ibama, 2001.

\section{Referências bibliográficas}

AraúJo, Luiz Alberto David. Direito constitucional e meio ambiente. Revista do Advogado, São Paulo, no 37, p. 63-70, 1992.

Armelin, Donaldo. Tutela jurisdicional do meio ambiente. Revista do Advogado, São Paulo, no 37, p. 48-62, 1992.

Assis, José Chacon de. Brasil 21: uma nova ética para o desenvolvimento. 6. ed. Rio de Janeiro: CREA-RJ, 2001.

Barbosa, Baltazar Gama. Poder de Polícia e Direito. Revista de Direito Administrativo, Rio de Janeiro, v. 54, p. 14-19, out./dez. 1958. 
BоввIо, Norberto et al. Dicionário de política. Brasília, DF: Unb, 1999. 2 v.

CaIrncross, Frances. Meio ambiente: custos e benefícios. São Paulo: Nobel, 1992.

CARVAlHo, Érika Mendes de. Tutela penal do patrimônio florestal brasileiro. São Paulo: Revista dos Tribunais, 1999.

CARvalho, Isabel Cristina de Moura. Em direção ao mundo da vida: interdisciplinaridade e educação ambiental/Conceitos para se fazer educação ambiental. Brasília: IPÊ/Instituto de Pesquisas Ecológicas, 1998.

Di PIetro, Maria Sylvia Zanella. Direito administrativo. São Paulo: Atlas, 1996.

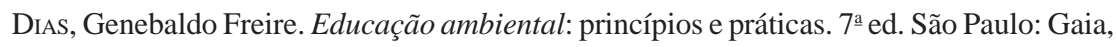
2001.

Dinamarco, Cândido Rangel. O Poder Judiciário e o meio ambiente. Revistas dos Tribunais, São Paulo, v. 631, p. 24-28, 1988.

FioriLlo, Celso Antônio Pacheco. A ação popular e a defesa do meio ambiente. Revista do Advogado, São Paulo, no 37, p. 27-35, 1992.

Folha de S. Paulo. Rio +10. Caderno Especial 1, 24 ago. 2002.

Franco, Maria de Assunção Ribeiro. Planejamento ambiental para cidade sustentável. São Paulo: Annablume; FAPESP, 2000.

Franco Sobrinho, Manuel de Oliveira. Tabelamento de preços - Poder de Polícia Competência da Administração - Intervenção do Estado na ordem econômica. Revista de Direito Administrativo, Rio de Janeiro, v. 24, p. 336-340, abr./jun. 1954.

Guevara, Arnoldo José de Hoyos et al. Conhecimento, cidadania e meio ambiente. São Paulo: Peirópolis, 1998. (Série Temas Transversais, v. 2).

LoPes, Inez Vidigal et al. Gestão ambiental no Brasil: experiência e sucesso. Rio de Janeiro: FGV, 1998.

MACHADO, Paulo Afonso Leme. Estudos de direito ambiental. São Paulo: Malheiros, 1994. Direito ambiental brasileiro. 10ª ed. São Paulo: Malheiros, 2002.

Madauar, Odete. Poder de Polícia. Revista de Direito Administrativo, Rio de Janeiro, v. 199, p. 89-96, jan./mar. 1995.

Martins, Fernandes. Poder de Polícia - Casa de diversões públicas. Revista de Direito Administrativo, Rio de Janeiro, v. 39, p. 258-264, jan./mar. 1955.

MazzILli, Hugo Nigro. Interesses coletivos e difusos. Revista dos Tribunais, São Paulo, v. 668, p. 47-57, 1991.

MedeIRos, Jarbas. O poder de polícia como fato gerador da cobrança de taxas. Revista de Direito Administrativo. Rio de Janeiro, v. 92, p. 414-442, abr./jun. 1968.

MeIrelles, Hely Lopes. Direito administrativo brasileiro. São Paulo: Malheiros, 1987.

. O poder de polícia, o desenvolvimento e a segurança nacional. Revista de Direito Administrativo, Rio de Janeiro, v. 125, p.1-14, jul./set.1976.

Mello, Celso Antônio Bandeia de. Curso de direito administrativo. São Paulo: Malheiros, 1994.

Milaré, Edis. Direito do ambiente: doutrina, prática, jurisprudência, glossário. $2^{\underline{a}}$ ed. São Paulo: Revista dos Tribunais, 2001.

Tutela jurisdicional do meio ambiente. Revista do Advogado, São Paulo, no 37, p. 5-18, 1992.

MukaI, Toshio. Direito ambiental sistematizado. $3^{\mathrm{a}}$ ed. Rio de Janeiro: Forense Universitária, 1998. 
NALINI, José Renato. Ética ambiental. Campinas: Millenium, 2001.

NERY JúnIOR, Nelson. Responsabilidade civil e meio ambiente. Revista do Advogado, São Paulo, no 37, p. 36-471, 1992.

Oliverra, Antônio Cláudio Mariz de. Direito penal e meio ambiente. Revista do Advogado, São Paulo, no 37, p. 19-26, 1992.

Pinho, Ruy Rebello; NAscimento, Amauri Mascaro. Instituições de direito público e privado. São Paulo: Atlas, 2000.

Ráo, Vicente. O direito e a vida dos direitos. São Paulo: Revista dos Tribunais, 1999.

SACHS, Ignacy. Caminhos para o desenvolvimento sustentável. Rio de Janeiro: Garamond, 2002.

SAlles, Carlos Alberto de. Execução judicial em matéria ambiental. São Paulo: Revista dos Tribunais, 1999.

Silva, José Afonso da. Poder de Polícia. Revista de Direito Administrativo, Rio de Janeiro, v. 132, p. 241-255, abr./jun.1978.

Sirvinskas, Luís Paulo. Manual de direito ambiental. São Paulo: Saraiva, 2002.

TÁcıтo, Caio. O poder de polícia e seus limites. Revista de Direito Administrativo, Rio de Janeiro, v. 27, p. 1-11, jan./mar. 1952.

TEMER, Michel. Elementos de direito constitucional. 15쯜. São Paulo: Malheiros, 1999.

Torres, Haroldo et al. População e meio ambiente: debates e desafios. São Paulo: Senac, 2000 . 


\section{Desenvolvimento sustentável: o desafio da admininstração pública brasileira nas dimensões da relevância social, da prudência ecológica e da viabilidade econômica}

\section{Anderson Macedo de Jesus}

Partindo do conceito de bem-estar social, definido em lei como de responsabilidade da administração pública, especialmente no que diz respeito à preservação dos recursos naturais para a manutenção da decente qualidade de vida dos cidadãos, $\mathrm{o}$ artigo foi estruturado a partir do relatório de pesquisa de iniciação científica financiada pela Fundação de Amparo à Pesquisa do Estado de São Paulo (Fapesp) e desenvolvido na Universidade Estadual de São Paulo (Unesp). Tal relatório objetivou investigar os parâmetros de regularidade da administração pública, analisando-se a jurisprudência dos tribunais. Foram evidenciadas irregularidades na atuação da administração pública, constatando a desarticulação da gestão pública ao gerir as três dimensões que definem o desenvolvimento sustentável: a relevância social, a viabilidade econômica e a prudência ecológica. Foi possível constatar com esta pesquisa que a administração pública brasileira dá mais importância para a questão econômica que às questões sociais e ambientais. Pudemos perceber que enquanto o meio ambiente é degradado e a sociedade prejudicada com a piora da qualidade de vida, o econômico vem sendo privilegiado constantemente. Sendo assim, evidenciaremos esse descaso propondo algumas mudanças para a melhora da gestão das três dimensões do desenvolvimento sustentável; porém, em contrapartida, mostraremos a seriedade na atuação dos órgãos colegiados ambientais e instituições do poder público, tais como o Ministério Público, que hoje atuam em parceria com a população, crescentemente envolvida no processo mediante a prática de denúncias e reclamações.

\section{Desarrollo sostenible: el desafío de la administración pública brasileña en las dimensiones de la importancia social, de la prudencia ecológica y de la viabilidad económica}

\section{Anderson Macedo de Jesus}

Partiendo del concepto de bien-estar social, definido en ley como de responsabilidad de la Administración Pública, especialmente en lo que concierne la preservación de los recursos naturales para el mantenimiento de la decente calidad de vida de los ciudadanos, el artículo fue estructurado a partir del informe de investigación científica financiada por la Fundación de Apoyo a la Investigación de la Provincia de São Paulo (Fapesp) y desarrollado en la Universidad Provincial de São Paulo, Unesp. Tal informe tuvo por objetivo investigar los parámetros de regularidad de la Administración Pública, analizando la jurisprudencia de los Tribunales. Fueron evidenciadas irregularidades en la actuación de la Administración Pública, constatando la desarticulación de la gestión pública al gestionar las tres dimensiones que definen el desarrollo sostenible: la relevancia social, la viabilidad económica y la prudencia ecológica. Fue posible constatar con esa investigación que la administración pública brasileña da mucho más importancia a la cuestión económica que a las cuestiones sociales y ambientales. Hemos podido percibir que mientras el medio ambiente es degradado y la sociedad es perjudicada con el empeoramiento de la calidad de vida, el económico viene siendo privilegiado constantemente. Así, evidenciaremos ese desinterés proponiendo algunos cambios para la mejoría de la gestión de las tres dimensiones del desarrollo sostenible; todavía, en contrapartida, mostraremos la seriedad en la actuación de los órganos colegiados ambientales e instituciones del poder público, tales como el Ministerio Público, que hoy actúan en sociedad con la población, crecientemente involucrada en el proceso por medio de la práctica de denuncias y reclamaciones.
Revista do

Serviço

Público

Ano 55

Número 4

Out-Dez 2004

\section{Anderson} Macedo de Jesus é Assessor Técnico da ENAP, graduado em Administração Pública pela Unesp, pósgraduando do curso de Especialização em Gestão Pública pela ENAP, professor convidado do curso de pósgraduação Lato sensu em Gestão Pública da Escola de Governo de Mato Grosso.

Contato: anderson.jesus@ enap.gov.br 

in the dimensions of the social relevance, the ecological prudence and the economic viability

Anderson Macedo de Jesus

Considering social welfare as a responsibility, established by law, of the Public Administration, this paper is about environment preservation in order to maintain a proper level of the citizen's life quality. The current study has its origin from a research done by the Fundação de Amparo à Pesquisa do Estado de São Paulo (Fapesp) and developed in the São Paulo State University, Unesp. Such report aims scrutinize the parameters of regularity of the public administration, by studying the precedents of the Courts. That scrutiny leads us to observe many irregularities in its performance, showing the failure of the institutions in managing the three dimensions that define the sustainable development: i) the social relevance; ii) the viability economic; and iii) the ecological prudence. It was possible to realize with that research the Brazilian public administration gives more importance to economy affairs to the social and environmental ones. We can realize that while the environment is depredated and the society damaged with the worse of quality life, the economy matter has always been privileged. We demonstrate show these situations and propose some changes in order to improve the management of those three dimensions of the sustainable development. On the other hand, we will illustrate the seriousness of the collegiate agencies, and others institutions of the public power, such as the Public Prosecution Office that act in partnership with the population, which already became involved by denouncing those vicious practices. 